\title{
The business process management software for successful quality management and organization: A case study from the University of Split School of Medicine
}

\author{
Damir Sapunar*, Ivica Grković, Davor Lukšić, Matko Marušić
}

University of Split School of Medicine Croatia

*Corresponding author:
ds@mefst.hr
Tel.: + 385 21557809
Fax.: +38521 557811

Received: 16 December 2015

Accepted: 6 April 2016

Key words: Medical education - Medical school - Organization - Quality management.

\begin{abstract}
Objective. Our aim was to describe a comprehensive model of internal quality management (QM) at a medical school founded on the business process analysis (BPA) software tool. Methods. BPA software tool was used as the core element for description of all working processes in our medical school, and subsequently the system served as the comprehensive model of internal QM. Results. The quality management system at the University of Split School of Medicine included the documentation and analysis of all business processes within the School. The analysis revealed 80 weak points related to one or several business processes. Conclusion. A precise analysis of medical school business processes allows identification of unfinished, unclear and inadequate points in these processes, and subsequently the respective improvements and increase of the QM level and ultimately a rationalization of the institution's work. Our approach offers a potential reference model for development of common QM framework allowing a continuous quality control, i.e. the adjustments and adaptation to contemporary educational needs of medical students.
\end{abstract}

\section{Introduction}

Medical education takes place in one of the most complex academic settings. This complexity is best envisaged by Flexner's triadic framework of education, research, and clinical care that has been a standard for the majority of medical schools for almost a century (1). Managing and providing support for these three major elements presents serious organizational challenges. In addition, the organization of medical schools and medical education faces general (e.g., continuous increase of demands) and specific (e.g., shortage of resources) problems of health care systems worldwide $(2,3)$. Today's health systems are struggling to keep up with increasing inequities in health care availability, new infectious agents, environmental, and behavioral risks, and rapid demographic and epidemiological transitions that threaten the health security of all (3).

All of these factors reflect on the cost of medical education, which is becoming increasingly demanding, complicated and expensive. According to an estimate for US medical schools, $\$ 62,877$ USD is the annual variable cost of educating a medical student (4). These costs are significantly lower in less developed countries but still present a substantial burden for the communities (5).

These problems impose a necessity of organizing better and more cost-efficient management of medical schools. One of the 
ways to achieve this is through the implementation of quality management (QM) system which become a prerequisite for high quality medical teaching, research and administration. The implementation should not only be limited to medical education but should encompass the overall organization of medical schools.

The QM approach initially emerged from industrial and commercial practices and gradually spread to other sectors (6). Universities and medical schools are now responsible for operating a quality management system that designs, delivers, monitors and assesses medical curricula to meet required standards $(7,8)$. These standards and requirements for QM in medical education are well defined (7, 8). However, there are no general guidelines for the implementation of these standards in medical education, including those defined by International Organization for Standardization (ISO) standard. As a consequence, numerous concepts of ISO standards implementation may exist in medical schools and health care institutions (9). Those standards often emphasize only the educational processes and neglect other important aspects of medical school organization.

Here we present our attempt to address the issue of QM in our medical school through implementation of the business process analysis (BPA) tool. The main aim was to document, analyze and streamline all business processes within our medical school as a first step in the IT-based development of a comprehensive QM system.

Here we describe the respective experience, the opportunities, the limits, and the perspectives that such a methodology allowed.

\section{Methods}

\section{Setting}

The University of Split School of Medicine is located in the city of Split, the second larg- est city in Croatia, and is one of four state owned medical schools in Croatia (10). All four schools are funded by the Ministry of Science, Education and Sports. The physician's education is based on a six-year integrated curriculum. The medical school in Split annually enrolls around 200 students in medicine, dental medicine and pharmacy courses.

\section{The process management approach}

With the objective of documenting and analyzing all business/work processes within the University of Split School of Medicine, a multidisciplinary work group was created, including health professionals, researchers, software engineers from the School's IT department and administrative staff members. The members of the work group were educated in business process management software by BPA professionals from Scheer GmbH Company (Saarbrucken, Germany). Upon training, all members of the work group were certified for business process modeling. The collaborative work was carried out in six phases: initial informative meetings, intensive training, process selection, definition of work method, process description by experts, and process modeling. Process description was prepared through interviews with the persons in charge of specific process by one member of the work team. The reduction of working hours was also estimated based on these interviews and was based on anticipated time saved by reducing number of unnecessary steps, documents and/or people involved.

\section{Tools}

BPA tools are primarily intended for users looking to document, analyze and streamline complex processes, thereby improving productivity, increasing quality and efficiency. These tools are also utilized by business 
process architects and business process analysts, who want to gain a deeper understanding of business processes, events, workflows and data using proven modeling techniques. BPA tools permit users to illustrate their processes and validate this information using standard methodologies and best practices allowed by the software. Ideally, it can automate the models into deployable applications that leverage their analytical efforts and comply with the business process rules. The ARIS platform (Architecture of Integrated Information Systems, Scheer, Saarbrucken, Germany) is the leading platform for BPA. The platform allows description and documentation of all business processes performed in a particular institution. The resulting repository of business/work processes represents a basis for development of future IT solution with the aim of process automation. Two products were used; ARIS Business Server and ARIS Business Architect, which constitute a tool for modeling, analysis and displaying business processes. The Server module allows several ARIS Business Architect users to work simultaneously on the database.

\section{Ethics statement}

The Helsinki Declaration is not applicable to the research presented in the manuscript since the presented research describes the business processes and did not involve human subjects or human data.

\section{Results}

First we included definitions of the processes gained by the respective School's personnel in the ARIS flowchart, and then analyzed them for completeness and unambiguity. This approach identified weaknesses that should have subsequently been corrected by the School's administration and experts.

\section{Structure and processes}

The overall structure of the medical school was described by the "entry model" defined by the following: a) Organization structure, b) Processes, c) Applications, d) Documents and e) Products and services. These elements are presented in the form of a "virtual institution" schematic diagram in which business processes constitute a central point, while documents and applications are depicted as pillars supporting the structure of the institution (Figure 1). The organization of the School covers the whole structure, while the basis of the School structure is presented by its products and services (Figure 1).

All business processes within the School were divided into three main categories of interlinked processes (Figure 2). The first category comprises the "key" or "core" processes that are directly related to the main school's purpose, as expressed in the School's Mission (i.e. education, scientific and professional work) (Figure 2). Secondly, the "supportive" processes are not directly linked with teaching, research, and clinical work, but are essential for the successful execution of "key" processes (e.g. library management, IT service, administrative and lagal support) (Figure 2). The third category

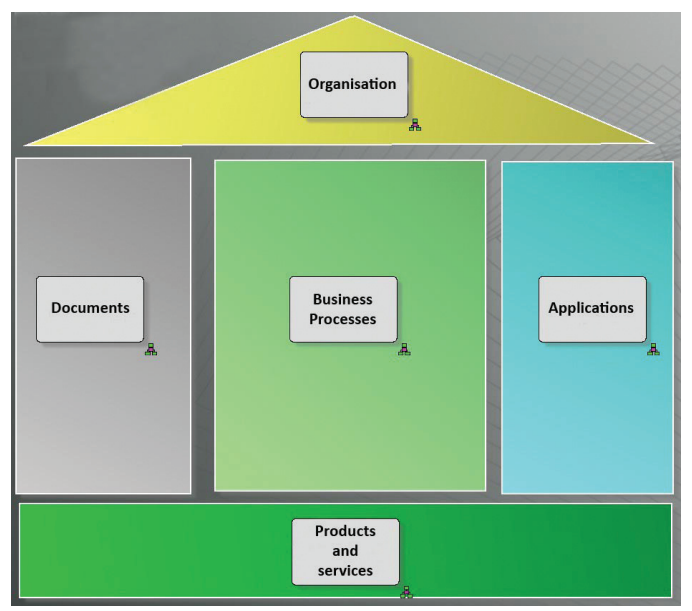

Figure 1 Entry model of medical school organization prepared according to the "business management approach". 


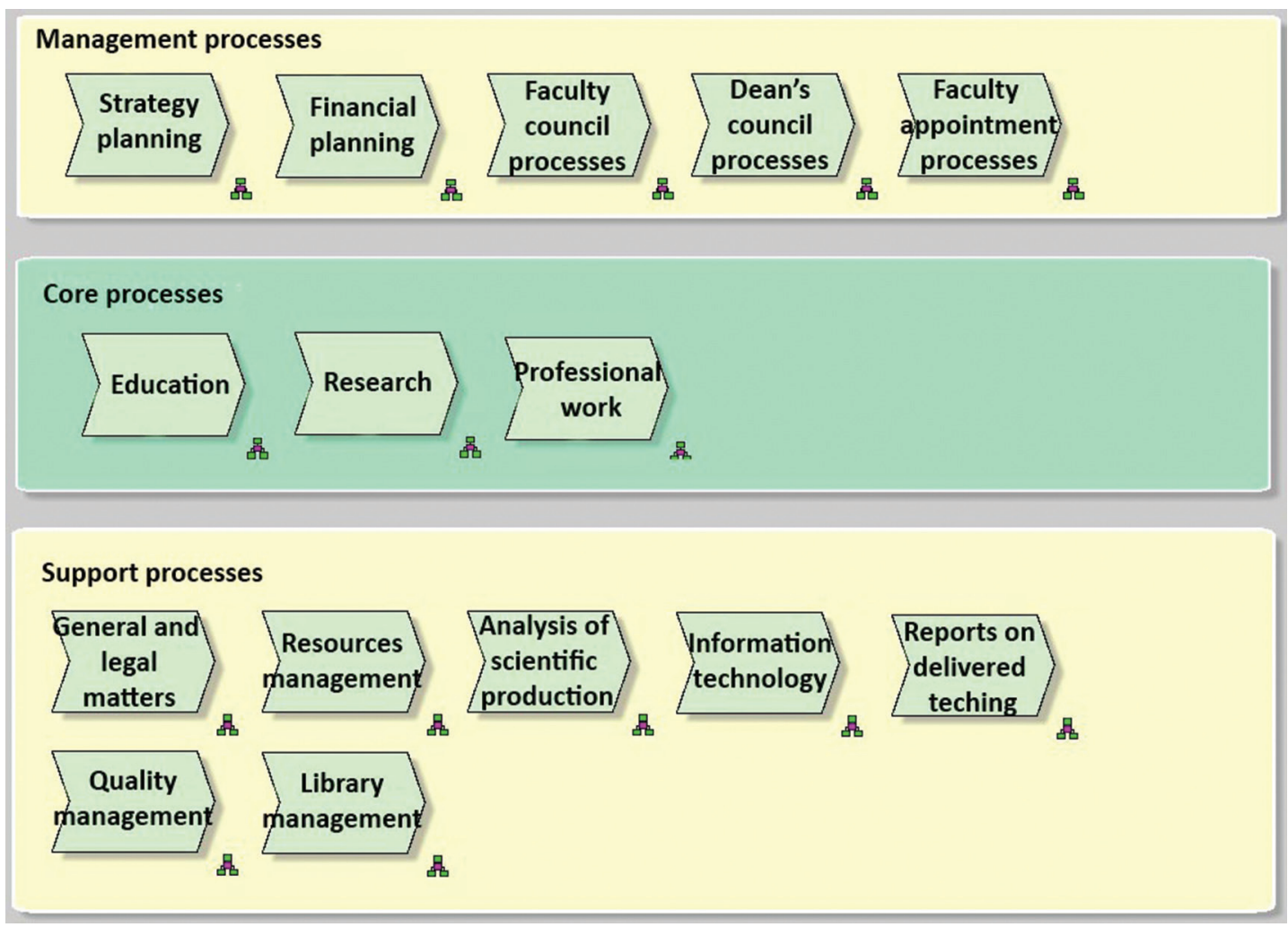

Figure 2 Three main categories of business processes within the medical school. Core processes encompass all activities directly related to the school's mission. The role of Supportive and Management processes is to allow successful execution of the core processes.

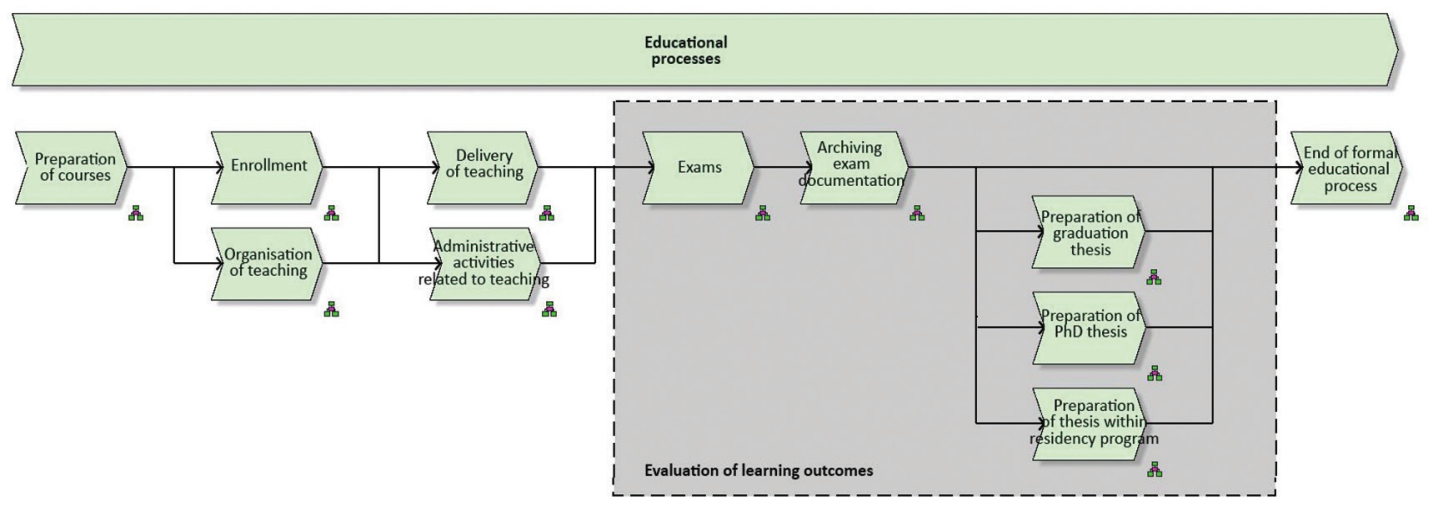

Figure 3 Example of Value added chain (VAC) diagram developed for educational processes.

encompasses institutional "management" processes (e.g., organization of the school council, or dean's cabinet meetings). The clustering was done according to the overall goal of the presented processes.

The business processes within each cluster were subdivided and presented through value added chain (VAC) diagrams, where each VAC diagram contained one or multiple sub-processes (Figure 3). Each element of the VAC ended up with the final process described through an "event driven process chain” (EPC) (Figure 4). In order to produce a detailed description of each EPC diagram, 

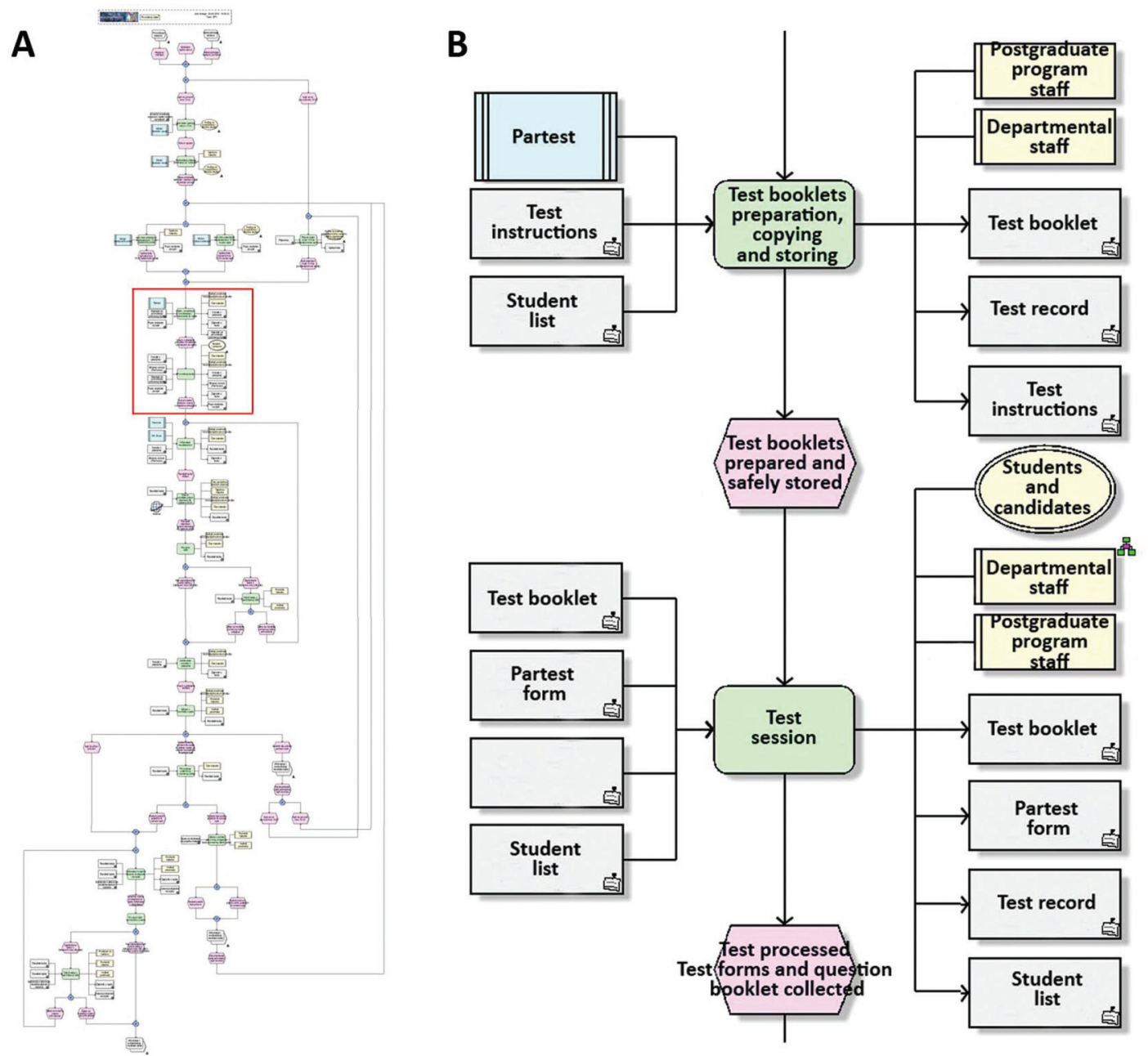

Figure 4 Example of Value added chain (VAC) diagram developed for the business process described as "Student testing". A) The left panel presents the whole structure of the business process. B) The selected part of the process represents a small segment marked with the red square on the left panel.

the processes were presented as series of attributes. The most important attributes were function, event, operators, responsible person or organizational unit, necessary documents or software application (Figure 4). The whole structure and all business processes can be accessed on the project website http://genom.mefst.hr/ARIS/.

\section{Detection of failures and weak points}

The analysis of the documented business processes revealed 80 weak points (WP, Table 1). The term weak point encompasses business processes that are missing or are deficient. The identified WPs were related to missing $(n=13)$ or incomplete $(n=19)$ processes, processes without defined deadlines $(\mathrm{n}=4)$ or even to processes which were in collision with current laws and institutional bylaws $(n=14)$. The remaining weak points were identified in processes that lacked description of involved persons / institutional units $(n=11)$, lack of necessary documents, archiving procedures or defined ways of making the results of the process available to stakeholders ( $\mathrm{n}=15)$, as well as lack of equipment or necessary software (Table 1). 
Table 1 The description and number of weak points encountered within the University of Split School of Medicine

\begin{tabular}{|c|c|c|c|c|c|c|c|c|}
\hline \multirow{2}{*}{ Weak points } & \multirow{2}{*}{$\begin{array}{l}\begin{array}{l}\text { Core } \\
\text { processes }\end{array} \\
\text { Education }\end{array}$} & \multicolumn{4}{|c|}{ Support processes } & \multicolumn{2}{|c|}{$\begin{array}{l}\text { Management } \\
\text { processes }\end{array}$} & \multirow{2}{*}{ Total } \\
\hline & & $\begin{array}{l}\text { General and } \\
\text { legal matters }\end{array}$ & $\begin{array}{l}\text { Resources } \\
\text { management }\end{array}$ & IT & $\begin{array}{l}\text { Quality } \\
\text { management }\end{array}$ & $\begin{array}{l}\text { Strategy } \\
\text { planning }\end{array}$ & $\begin{array}{l}\text { Financial } \\
\text { planning }\end{array}$ & \\
\hline Lack of process & 2 & 1 & 5 & 2 & 1 & 1 & 1 & 13 \\
\hline $\begin{array}{l}\text { Lack of equipment / } \\
\text { software }\end{array}$ & - & 1 & 1 & 2 & - & - & - & 4 \\
\hline Incomplete process & 10 & 2 & 5 & 2 & - & - & - & 19 \\
\hline $\begin{array}{l}\text { Document / web } \\
\text { management } \\
\text { problem }\end{array}$ & 4 & 2 & - & 2 & 7 & - & - & 15 \\
\hline $\begin{array}{l}\text { Collision with } \\
\text { laws / institutional } \\
\text { bylaws }\end{array}$ & 7 & 2 & 5 & - & - & - & - & 14 \\
\hline No defined deadline & - & 1 & 1 & 2 & - & - & - & 4 \\
\hline $\begin{array}{l}\text { Person or institutional } \\
\text { unit not defined }\end{array}$ & 10 & - & 1 & - & - & - & - & 11 \\
\hline Total & 33 & 9 & 18 & 10 & 8 & 1 & 1 & 80 \\
\hline
\end{tabular}

\section{Analysis of weak points}

The analysis of identified weak points revealed processes which could be substantially shortened by reducing number of unnecessary steps, documents and/or people involved. The analysis was performed by modeling and the comparison of current ("as is") and modeled ("as if") business processes. A precise analysis allowed us to determine the reduction of costs and/or working hours for

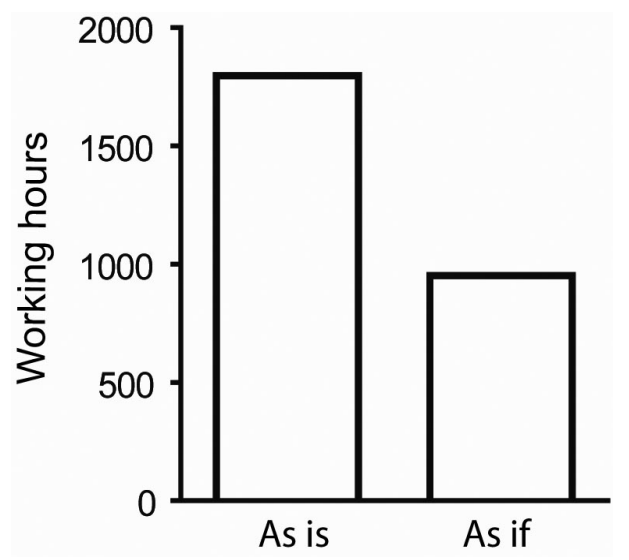

Figure 5 Example of improvement modeling of business processes related to purchasing procedures. Improvement is presented as reduction in working hours between "as is" and "as if" conditions. specific processes upon improvement. As an example, the Figure 5 depicts the reduction of the working time necessary for purchasing procedures. Improvement of purchasing processes resulted in 53\% reduction in working hours for that specific process.

The actual improvements based on implementation of the analysis of the weak points depended on the readiness of the school management to enforce these changes, attitude towards changes of the current school management, financial issues, and priorities set up by different school managements.

\section{Discussion}

The ARIS platform provides a suitable BPA tool for the medical school setting, and we believe that it may be used as a possible reference model for developing common QM frameworks according to the plan-dostudy-act (PDSA) cycle of continuous improvement (11).

Our present work is the first step in QM implementation within the University of Split School of Medicine. Its main result was 
the description and analysis of all business/ work processes within the School. The application of the ARIS BPA tool helped the School start its own QM system as an initial step towards a comprehensive QM system.

There is no single (or simple) definition of quality, inasmuch as this term has different meanings to different professionals (12, 13). The issue of QM in higher and medical education has been the objective of many international organizations, including the European Association for QA in Higher Education (ENQA) and the World Federation for Medical Education (WFME) which developed a set of standards, procedures and guidelines on QM $(7,8,14)$. QM of medical education implies a well-planned assessment of the structure, process and the outcome of education based on defined standards and objectives.

Published examples of business process modeling in medical education and health care practice are scarce (15-20), and none of them presents a comprehensive documentation and analysis of processes within the whole institution. In most cases these examples present a small segment of business processes generally oriented only towards educational processes, while neglecting other important processes such as management, research or support.

In our opinion this presents serious drawbacks because a segmented approach seriously limits the potential for the implementation of IT solutions that can manage business/work operations and customer satisfaction. We adopted a different, comprehensive, "business-oriented" approach, inasmuch as we have been aware that efficacy of the educational processes depend on the workflow and harmonization of all supporting processes in the medical school. However, to our knowledge, this notion has not been tested directly.

Quality management practices in the Croatian academic community have never been adopted in full. In 2005 the Croatian Parliament established the Agency for Science and Higher Education (AZVO) that has been organizing a system of quality assurance in higher education and science. AZVO is the key institution performing external accreditation of academic institutions according to ISO 9001:2008 standard. In 2009 the State Parliament introduced a legal act regarding quality assurance in science and higher education, (21) but academic institutions still did not adopt proper mechanisms of QM. However, most of the proposed activities are related to accreditation procedures and not to other aspects of QM.

In conclusion, we have shown that existing business process analysis tools can be important part of quality management implementation in medical schools. Precise analysis of medical school business processes allows identification of weak points for specific processes that need improvement. Our approach can be considered a possible reference model for the development of a common QM framework which will allow for continuous quality control, adjustments and adaptation in medical schools and other higher education institutions.

\section{What is already known on this topic}

The quality management is necessary for organizing better and more cost-efficient management of medical schools. The standards and requirements for quality management in medical education are well defined, but other important aspects like professional, scientific, support and management processes within medical school organization are completely neglected.

\section{What this study adds}

The study presents description and analysis of all business processes within our medical school. That analysis can be considered as a first step in the development of a comprehensive quality management system. The business process analysis tools are important part of quality management implementation in medical schools. Precise analysis of medical school business processes allows the rationalization of working hours for specific processes that need improvement.

Acknowledgements: The members of the project team that developed database of business processes at the University of Split School of Medicine were: Davor 
Lukšić, Frane Mihanović, Vana Košta, Lana Barać, Josip Barić, Asija Petrašić and Mijo Kardum from the IDS Scheer. The head of the project team were Damir Sapunar and Katarina Dobronić from the IDS Scheer.

Authors' contribution: Conception and design: DS, IG, DL, and MM; Acquisition, analysis and interpretation of data: DS, IG, DL and MM Drafting the article: DS; Revising it critically for intellectual content: IG, DL and MM; Approval of final version to be published: DS, IG, DL and MM.

Conflict of interest: The authors declare that they have no conflict of interest.

\section{References}

1. Flexner A. Medical Education in the United States and Canada: A Report to the Carnegie Foundation for the Advancement of Teaching in Bulletin. Boston: The Merrymount Press; 1910.

2. Chen L, Berlinguer G. Health equity in a globalizing world. In: Evans T, Whitehead M, Diderichsen F, Bhuiya A, Wirth $\mathrm{M}$, editors. Challenging inequities in health: from ethics to action. New York: Oxford University Press; 2001. p. 35-44.

3. Frenk J, Chen L, Bhutta ZA, Cohen J, Crisp N, Evans T, et al. Health professionals for a new century: transforming education to strengthen health systems in an interdependent world. Lancet. 2010;376(9756):1923-58.

4. Schieffler DA, Azevedo BM, Culbertson RA, Kahn MJ. Financial implications of increasing medical school class size: does tuition cover cost? Perm J. 2012;16(2):10-4.

5. Maslov Kruzicevic S, Barisic KJ, Banozic A, Esteban CD, Sapunar D, Puljak L. Predictors of attrition and academic success of medical students: a 30-year retrospective study. PLoS One. 2012;7(6):e39144.

6 Barrows H, Tamblyn R. Problem-based learning: an approach to medical education. Medical Education. New York: Springer Publishing Company; 1980.

7. WFME - World Federation for Medical Education. Postgraduate medical education - WFME global standards for quality improvement. Copenhagen: Kandrups Bogtrykkeri; 2003.

8. ENQA - European Association for Quality Assurance in Higher Education. Standards and Guidelines for Quality Assurance in the European Higher Education Area. Brussels: ENQA; 2015.
9. Sweeney J, Heaton C. Interpretation and variations of IS 9000 in acute health care. Int J Qual Health Care. 2000;12(3):203-9.

10. Grkovic I, Sapunar D, Marusic M. Ways to address the challenges of a modern medical curriculum: living academic medicine at the University of Split, School of Medicine. Acta Med Acad. 2012;41(1):7-17.

11. Moen RD, Norman CL. Clearing up myths about the Deming cycle and seeing how it keeps evolving. Quality Progress. 2010;11:22-8.

12. Tariq M, Ali SA. Quality assurance and its application in medical education. J Coll Physicians Surg Pak. 2014;24(3):151-2.

13. Joshi MA. Quality assurance in medical education. Indian J Pharmacol. 2012;44(3):285-7.

14. Eriksen SD. TQM and the transformation from an elite to a mass system of higher education in the UK. Qual Assur Educ. 1995;3(1):14-29.

15. Rojo MG, Rolon E, Calahorra L, Garcia FO, Sanchez RP, Ruiz F, et al. Implementation of the Business Process Modelling Notation (BPMN) in the modelling of anatomic pathology processes. Diagn Pathol. 2008;3(Suppl 1):S22.

16. Dieter PE. Quality management of medical education at the Carl Gustav Carus Faculty of Medicine, University of Technology, Dresden. Ann Acad Med Singapore. 2008;37(12):1038-40.

17. Dieter PE. A faculty development program can result in an improvement of the quality and output in medical educaton, basic science and clinical research and patient care. Med Tech. 2009;31(7):566-9.

18. Scheuerlein H, Rauchfuss F, Dittmar Y, Molle R, Lehmann T, Pienkos N, et al. New methods for clinical pathways-Business Process Modeling Notation (BPMN) and Tangible Business Process Modeling. Langenbecks Arch Surg. 2012;397(5):755-61.

19. McClintock DS, Lee RE, Gilbertson JR. Using computerized workflow simulations to assess the feasibility of whole slide imaging full adoption in a high-volume histology laboratory. Anal Cell Pathol (Amst). 2012;35(1):57-64.

20. Barbagallo S, Corradi L, de Ville de Goyet J, Iannucci M, Porro I, Rosso N, et al. Optimization and planning of operating theatre activities: an original definition of pathways and process modeling. BMC Med Inform Decis Mak. 2015;15:38.

21. Law on Quality Assurance in Science and Higher Education [in Croatian]. Narodne Novine; 45:2009. 